\title{
Ventilation During Cardiopulmonary Resuscitation: What Have We Learned From Models?
}

\author{
Emmanuel Charbonney, Domenico L Grieco, Ricardo Luiz Cordioli, Bilal Badat, \\ Dominique Savary, and Jean-Christophe M Richard; on behalf of the CAVIAR Group
}

\author{
Introduction \\ New Hypotheses Based on Clinical Observations \\ Chest Compression-Related Ventilation \\ Thoracic Airway Closure and Lung Volume Reduction \\ What Have Different Models Taught Us? \\ Bench Models of CPR Relative to Functional Residual Capacity \\ Ventilation and Interaction With Circulation in Animal Models \\ From Clinical Observation to Human Model (Cadaver) \\ Alveolar Ventilation Produced by Chest Compressions \\ Capnography During CPR \\ Perspectives \\ Summary
}

\begin{abstract}
The optimization of ventilation during cardiopulmonary resuscitation (CPR) is a broad field of research. Recent physiological observations in this field challenge the current understanding of respiratory and circulatory interactions. Thanks to different models available (bench, animal, human), the understanding of physiological phenomena occurring during CPR has progressed. In this review, we describe the clinical observations that have led to the emerging concept of lung volume reduction and associated thoracic airway closure. We summarize the clinical and animal observations supporting these concepts. We then discuss the different contributions of bench, animal, and human models to the understanding of airway closure and their impact on intrathoracic pressure, airway closure, and hemodynamics generated by chest compression. The limitation of airway pressure and ventilation, resulting from airway closure reproducible in models, may play a major role in ventilation and gas exchange impairment observed during prolonged resuscitation. Key words: ventilation; cardiac arrest; airway closure; PEEP; intrathoracic pressure; perfusion; CPR; chest compressions. [Respir Care 2019;64(9):1132-1138. @ 2019 Daedalus Enterprises]
\end{abstract}

\section{Introduction}

The most recent developments in advanced cardiopulmonary resuscitation (CPR) have only led to slight im-

Dr Charbonney is affiliated with the Université de Montréal, and the Laboratoire d'anatomie, Université du Québec à Trois-Rivières (UQTR), Québec, Canada. Dr Grieco is affiliated with the Department of Anesthesiology and Intensive Care Medicine, Catholic University of The Sacred Heart, Fondazione 'Policlinico Universitario A Gemelli' IRCCS, provements in the outcome of patients experiencing cardiac arrest. ${ }^{1,2}$ Regarding the optimum treatment of cardiac arrest, the application of ventilation during CPR remains a field of uncertainty, ${ }^{3}$ with a substantial lack of robust ev-

Rome, Italy. Dr Cordioli is affiliated with the Department of Critical Care, Intensive Care Unit, Israelita Hospital Albert Einstein Sao Paulo, and the Department of Critical Care, Intensive Care Unit, Alemao Hospital Oswaldo Cruz Sao Paulo, Sao Paulo, Brazil. Mr Badat is affiliated 


\section{Ventilation DURING CPR}

idence and conclusive recommendations. ${ }^{4-7}$ Indeed, most of the studies on ventilation during CPR have focused on its interaction with the efficacy of chest compressions and hemodynamic consequences. ${ }^{8}$ Very little is known about the physiological effects of ventilation delivery during CPR, meaning that a comprehensive understanding of its role is still lacking. ${ }^{4}$

After the initial phase of CPR, ventilation is essential to ensure adequate oxygenation and $\mathrm{CO}_{2}$ washout. With the debate surrounding continuous chest compressions to enhance the hemodynamic efficacy of CPR, the understanding of ventilation in models representing human physiology have been neglected. ${ }^{9}$ Whether and to what extent the change in intrathoracic pressure generated by chest compressions is capable of producing alveolar ventilation has not been fully elucidated and remains controversial, but this could represent a crucial aspect of CPR. For this reason, a deeper understanding of human respiratory system behavior during CPR is warranted.

In this review, we discuss how the most recent bench, animal, and human cadaver models offer new physiological understanding of CPR, particularly regarding the interaction between ventilation and chest compressions.

\section{New Hypothesis Based on Clinical Observations}

\section{Chest Compression-Related Ventilation}

In 1961, Safar et al ${ }^{10}$ reported that the substantial ventilation generated by chest compressions in healthy volunteers undergoing simulated CPR was reduced to almost nothing in cardiac arrest patients. This observation suggested that a change in respiratory system behavior could play an important role in the limitation of ventilation produced by the variation of intrathoracic pressure secondary

with Air Liquide Medical Systems, Antony, France. Drs Savary and Richard are affiliated with SAMU74, Emergency Department, General Hospital of Annecy, Annecy, France. Dr Richard is also affiliated with INSERM UMR 1066, Créteil, France.

Dr Grieco discloses relationships with SIAARTI/Merck Sharp \& Dohme, ESICM by Maquet, Getinge, Air Liquide, and GE Health Care. Dr Cordioli discloses a relationship with Air Liquide Medical Systems. Mr Badat is an employee of Air Liquide Medical Systems. Dr Savary discloses relationships with Air Liquide Medical Systems and Vygon. Dr Richard discloses relationships with Air Liquide Medical Systems, Vygon, Drager, and Covidien. Dr Charbonney has disclosed no conflicts of interest.

Correspondence: Emmanuel Charbonney MD PhD, Hôpital du SacréCoeur de Montréal, 5400 Boulevard Gouin Ouest, Montréal, Québec, H4J 1C5, Canada. E-mail: emmanuel.charbonney@umontreal.ca.

DOI: $10.4187 /$ respcare.06998 to external chest compressions. Since the first report, other authors have demonstrated that chest compressions could generate variable tidal volumes that were often lower than dead space. ${ }^{11,12}$ The mechanisms regulating the capability of chest compressions to produce alveolar ventilation had never been thoroughly investigated until recent observations. It is of great interest because animal models have shown that progressive hypoxemia, hypercapnia, and acidemia develop if adequate ventilation is not provided during prolonged CPR. ${ }^{13-15}$ In contrast, some authors reported that continuous flow insufflation, providing a small amount of positive airway pressure, allowed adequate gas exchange during human CPR with minimal impact on circulation. ${ }^{16,17}$

Thanks to a recent series of studies conducted on bench and human cadaver models, new hypotheses have been generated to explain these observations, based on a better understanding of respiratory system and airway response to chest compressions.

\section{Thoracic Airway Closure and Lung Volume Reduction}

In 5 out-of-hospital cardiac arrest subjects, Cordioli et al ${ }^{18}$ recorded extremely low ventilation associated with chest compressions, depicting a typical inspiratory flow-limited tracing during chest decompression at zero PEEP. The physiological explanation was that the lung volume reduction below the end-expiratory thoracic volume induced by chest compressions may provoke the closure of distal airways, leading to flow limitation. Similar results have also been indirectly suggested by other groups, but the exact mechanism has not been explicated and may be partially misinterpreted. ${ }^{12,19}$ These findings are consistent, however, with classical physiological descriptions, which report that airways are likely to collapse as end-expiratory lung volume falls below the closing capacity. ${ }^{20}$ Hence, intrathoracic airway closure is also documented during ARDS, which is characterized by lung volume loss, reduced functional residual capacity (FRC) due to alveolar flooding, and inflammatory edema. ${ }^{21,22}$ In cardiac arrest patients, the lung volume reduction due to chest compressions is possibly enhanced by the loss of chest wall muscle tone.

These observations led to the hypothesis that lung volume is reduced during CPR and may result in intrathoracic airway closure, which may explain the low ventilation and gas exchange impairment often with during prolonged resuscitation. Results of experimental studies done in bench, animal, and human models supporting this theory are discussed in the following sections. 


\section{VENTILATION DURING CPR}

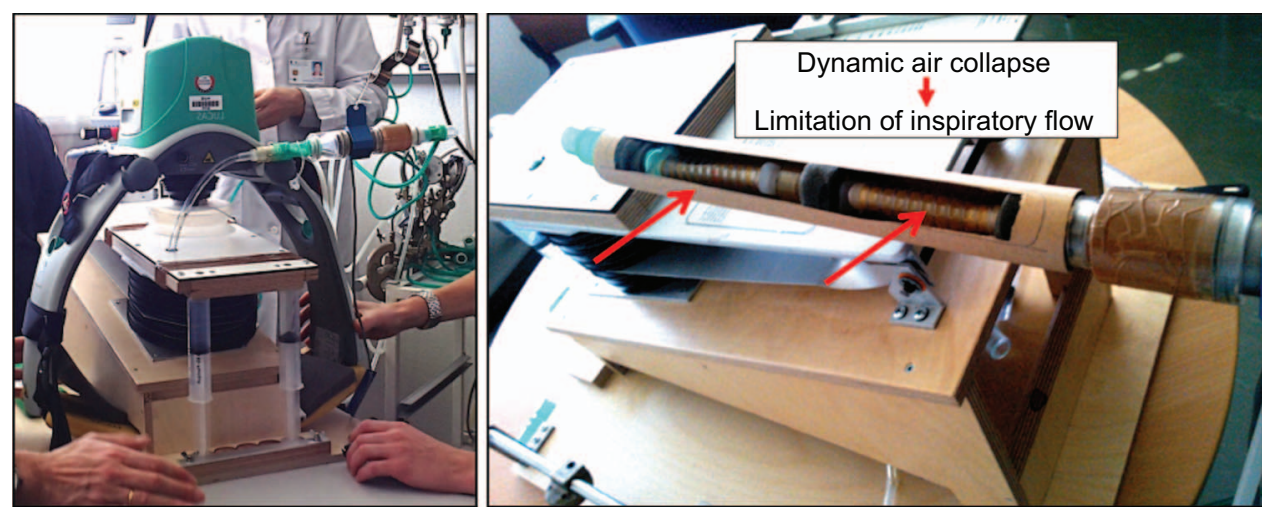

Fig. 1. Mechanical lung model mounted on bellows and spring, designed to reproduce the physical properties of the thoracic compartment and to perform chest compressions. The artificial lung is connected to a compressible conducting airway connector to mimic airway collapse. Chest compressions are applied using a mechanical device (LUCAS 2). The precise description of the system and experiments are reported in Reference 18.

\section{What Have Different Models Taught Us?}

\section{Bench Models of CPR Relative to FRC}

An original thoracic lung model was designed to reproduce the mechanical properties of the thoracic compartment (ie, lung, airways, and thorax) during CPR, and this model was intentionally shaped to permit chest compressions (Fig. 1). ${ }^{18}$

This model allows chest compressions to start from FRC and mimics the elastic recoil of the thorax during both the compression phase and the decompression phase of CPR. In addition, a compressible conducting connector applied at the airways creates a Starling resistor, which replicates airway collapse when the transmural pressure (ie, airway pressure surrounding pressure) becomes $<0$. A dedicated mechanical device is used to standardize chest compressions (LUCAS 2, Jolife AB/Physio-Control, Lund, Sweden). The settings allow the assessment of the effects of different ventilation strategies under comparable conditions of chest compressions.

In this study, tidal ventilation occurred at absolute lung volumes that were less than functional residual capacity. The results indicate that inspiration is expected to take place during thorax decompression because inspiratory flow occurs as a consequence of recoil pressure, while expiration occurs during chest compressions. Flow entering the thorax is limited by the collapsibility of the resistor that is mimicking airway closure, but this can be partially restored by the application of positive pressure at the airway opening; the latter also limits lung volume reduction, thereby facilitating alveolar ventilation. ${ }^{18}$

These observations, obtained in a model approximating physiology, were indirectly supported by the previously discussed clinical observations, showing significant lung volume reduction during CPR. The important limitation of this model is the extreme negative pressure induced by chest decompression in the system, which directly reflects the recoil forces. As discussed by Moore et al, ${ }^{23}$ such negative pressure in the airways/thoracic compartment has never been reported in vivo. It is likely that the complex interaction between lungs and chest wall mitigates the negative pressure measured in the pleural space during chest decompression. Nevertheless, this artificial model described for the first time the theoretical behavior of the respiratory system during chest compressions. Of particular note is that ventilation during CPR was taking place below functional residual capacity, with inspiration occurring during negative airway pressure.

\section{Ventilation and Interaction With Circulation in Animal Models}

In animal models, the decline over time of ventilation produced by chest compressions alone has been reported in swine. ${ }^{15}$ Using dynamic computed tomography series in a pig model with ventricular fibrillation, Markstaller et $\mathrm{al}^{24}$ showed that chest compressions alone led to large atelectatic areas and lower $\mathrm{P}_{\mathrm{aO}}$ compared to animals actively ventilated early during CPR. Interestingly, in similar animal models, Brochard et al ${ }^{17}$ showed that positive airway pressure permitted the maintenance of efficient ventilation and adequate gas exchange with chest compressions only. These seemingly conflicting results may be explained by the major effect of positive airway pressure that could reverse airway closure and other impairments of the respiratory system during CPR.

Nevertheless, the debate on ventilation in animal models revolves around the effect of PEEP on perfusion, but with conflicting results. The potential negative effect of PEEP on blood flow during CPR comes from animal studies suggesting that it impairs venous return. ${ }^{25} \mathrm{On}$ the other hand, despite concerns regarding the circulatory effects of 


\section{Ventilation DURING CPR}

positive pressure, authors have observed a beneficial impact on survival, especially after asphyxial cardiac arrest. 13,26,27 This may be explained by the beneficial effect of PEEP to increase functional residual capacity and improve systemic oxygenation in a cardiac arrest model that directly result from severe respiratory failure.

To help reconcile the conflicting results obtained in animal models regarding circulatory and ventilatory effects of PEEP, the behavior of the animal respiratory systems during chest compressions should be better investigated. In fact, due to the differences between the shape of the thorax, distal bronchial tree architecture, and alveolar connections in swine compared to humans, one can't exclude that lung volume reduction and airway collapse may be less frequent, at least at the early stage of CPR. These distinctions are important because pigs are the most frequently used animal model for research on CPR.28 To our knowledge, none of the animal studies have tested interventions after prolonged $\mathrm{CPR}$, which could have allowed sufficient time for these phenomena to occur. Only one model of dogs receiving CPR, using external vest inflation and deflation, reported air trapping. ${ }^{29}$

Finally, the most important concept regarding the impact of ventilation on circulation during CPR comes from animal studies describing the thoracic pump theory. During chest compressions, the chest recoil effect on intrathoracic pressure oscillation improves hemodynamics. ${ }^{30}$ Indeed, incomplete chest wall decompression has a negative impact on perfusion pressure, ${ }^{31}$ and active compressiondecompression improves it. ${ }^{32}$

In an attempt to enhance the phenomenon of chest recoil during decompression with enhanced venous return through negative intrathoracic pressure, several investigators have used an active compression-decompression strategy with the use of a threshold valve to create negative pressure through the airways and thus improve circulation. ${ }^{33}$ Interestingly, when active compression-decompression CPR with the use of an inspiratory impedance threshold valve was applied in a pig model, incremental PEEP improved oxygenation and left ventricular coronary perfusion pressure. ${ }^{34}$ To explain these observations, one can hypothesize that lung volume loss expected with the threshold valve and the potential associated airway collapse may be partially relieved by PEEP. Another study in swine, which used constant positive pressure with continuous oxygen insufflation $(15 \mathrm{~L} / \mathrm{min})$, did not show any difference in hemodynamics compared to chest compressions alone. Only the active compression-decompression CPR with the use of a threshold valve improved coronary and cerebral perfusion pressure. ${ }^{23}$ Nevertheless, ventilation with continuous flow insufflation in that study was not sufficient to maintain adequate gas exchange and efficient $\mathrm{CO}_{2}$ elimination. It is therefore of paramount importance to better understand the difference between animal and human models regarding ventilation during CPR.

\section{From Clinical Observation to Human Model (Cadaver)}

As previously discussed, the first observation of lung volume reduction during chest compressions (average of $335 \mathrm{~mL}$ ) and associated intrathoracic airway closure was found in out-of-hospital cardiac arrest subjects. ${ }^{18}$ Recently, fresh and treated cadavers have been proposed as a model for studying CPR. ${ }^{35}$ Among these, soft embalmed Thiel cadavers, which retain the body's natural look and feel, are reported to reliably reproduce human respiratory mechanics during cardiac arrest, thereby allowing realistic measurement during CPR. ${ }^{36,37}$

One important advantage of the human cadaver model, besides its capacity to reflect human respiratory physiology, is the possibility to measure the intrathoracic pressure changes (ie, the pressure that drives the vascular pressure produced by chest compressions) with the help of esophageal manometry. ${ }^{38} \mathrm{In}$ addition, realistic simulation of $\mathrm{CO}_{2}$ elimination and $\mathrm{P}_{\mathrm{ETCO}_{2}}$ waveform analysis can be done with this model (Fig. 2).37,38

\section{Alveolar Ventilation Produced by Chest Compressions}

As discussed at the beginning of this article, the tidal volume produced by chest compressions is extremely variable and is often lower than dead space, including after endotracheal intubation. ${ }^{11,12}$ It is known that CPR yields significant alveolar de-recruitment and a reduction in compliance. ${ }^{18,36,39}$ According to classic physiology, when lung volume decreases below a threshold value (ie, the closing capacity), small distal airways are likely to collapse; this could also be due to gas-liquid interfacing in small airways. ${ }^{21}$ Using a Thiel cadaver model, our group reported the existence of reproducible intrathoracic airway closure during CPR in humans. ${ }^{36}$

In the presence of this intrathoracic airway closure, negative alveolar pressure produced by chest decompressions (recoil) is no longer transmitted to the airway opening, and no inspiratory flow is generated despite a significant pressure gradient; hence, no inspiratory tidal volume can be produced during the decompression phase of CPR (Fig. 3). Moreover, in the case of airway closure, the increase in airway pressure produced by positive-pressure ventilation is mostly required to re-open the airways. This means that intrathoracic airway closure may prevent ventilation, independent of the chest compressions strategy used.

In our model, we showed that the application of a small degree of PEEP to maintain airway patency permits the transmission of a pressure gradient produced by chest wall 


\section{VENTILATION DURING CPR}

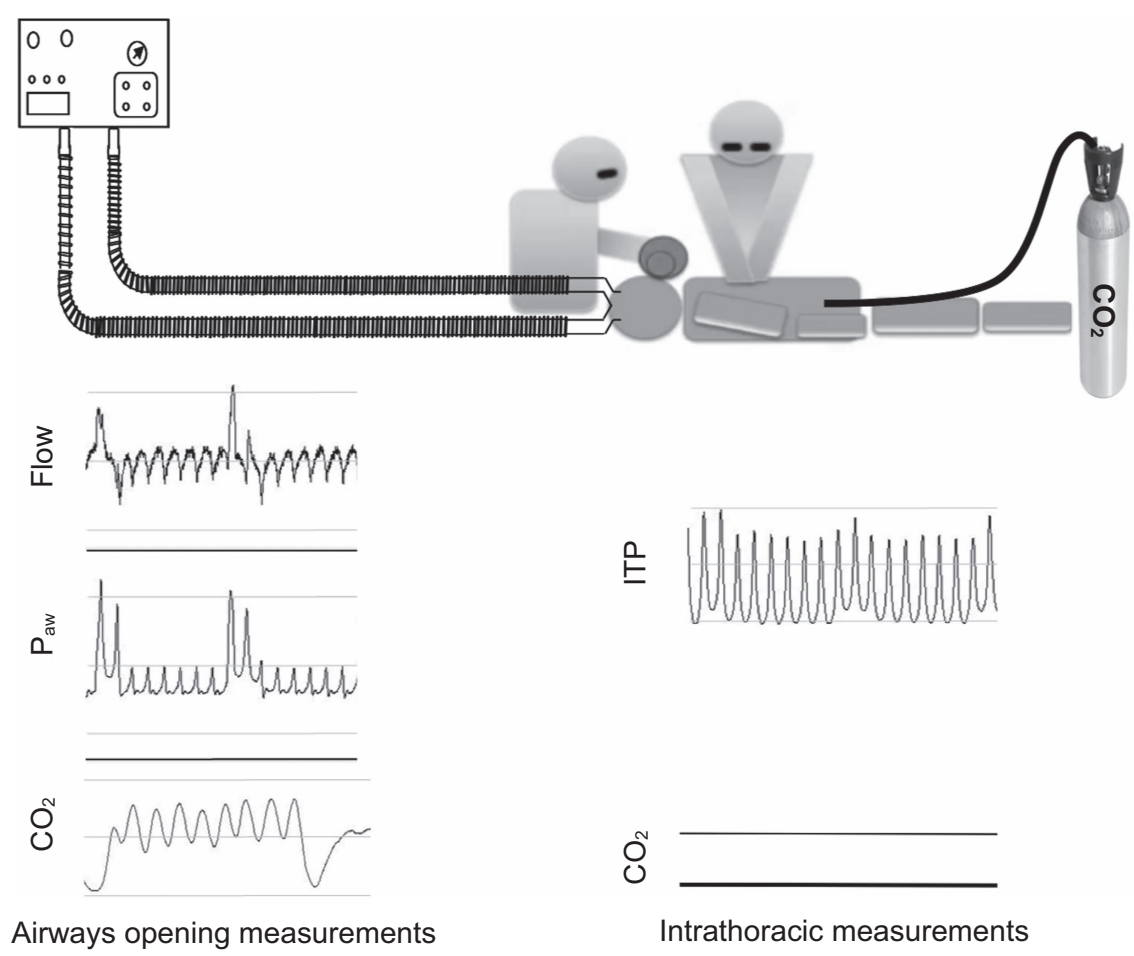

Fig. 2. Experimental settings of the Thiel cadaver model. Flow and airway pressure measured at the airway opening were derived from a pneumotachometer. The $\mathrm{CO}_{2}$ pattern was derived from capnography; $\mathrm{CO}_{2}$ is delivered directly into the distal trachea (continuous flow: flat line). Continuous measures of intrathoracic pressure changes during chest compressions were made with the use of an esophageal catheter. $\mathrm{P}_{\mathrm{aw}}=$ airway pressure; ITP = intrathoracic pressure.

recoil to airway opening (Fig. 3), thereby enabling an inspired tidal volume and effective alveolar ventilation. ${ }^{38}$ Regarding the impact of PEEP on the intrathoracic pressure levels and variations, further investigation is needed. As for the hemodynamic effect, no data exist in human subjects; the only hint comes from patients under anesthesia, where the application of PEEP does not change the venous return gradient in case of planned fibrillation. ${ }^{40}$

\section{Capnography During CPR}

Because airway patency yields fresh gas flow in the system and airway closure impedes it, the existence of an intrathoracic airway closure can be noninvasively estimated by analysis of the $\mathrm{CO}_{2} /$ time waveform, using capnography systems during chest compressions. ${ }^{9}$

To reproduce the capnography distorted by chest compressions that we observed in real cardiac arrest patients, we set up an original bench and cadaver model incorporating $\mathrm{CO}_{2}$ production. ${ }^{38}$ The idea was to simulate $\mathrm{CO}_{2}$ production to understand the physiological meaning of capnography patterns recorded at the airway opening.

When airways are patent, $\mathrm{CO}_{2}$ concentration at airway opening falls during decompression because fresh gas flow enters the system, resulting in capnography oscillating steadily with the rate of chest compressions. When airways are closed, $\mathrm{CO}_{2}$ at airway opening is stable, resulting in non-oscillating capnography (Fig. 3). Similar "distorted" capnography by chest compressions have been reported by Gutiérrez et al. ${ }^{41}$ Interestingly, non-oscillating capnography (suggesting airway closure) was observed in almost $60 \%$ of the subjects in this series, compared to $<30 \%$ in the series from Grieco et al, ${ }^{38}$ where subjects were ventilated with $5 \mathrm{~cm} \mathrm{H}_{2} \mathrm{O}$ of PEEP. The airway opening index, based on capnographic analysis and assessing the degree of oscillations in the $\mathrm{CO}_{2}$ signal, has been proposed by our group to detect airway closure during CPR. The use of PEEP after intubation during chest compressions consistently maintains airway patency, increases the airway opening index, and enhances alveolar ventilation produced by chest compressions. No effect is expected, neither harmful nor beneficial, when PEEP is set close to thoracic airway closure because the pressure in that case is transmitted minimally to the thorax. These findings open new opportunities to test ventilatory strategies that will impact the $\mathrm{CO}_{2}$ pattern during CPR.

Overall, the development of a realistic human model to study respiratory physiology during CPR has revealed new concepts regarding the interaction between intrathoracic pressure and transmission to the airway opening. 

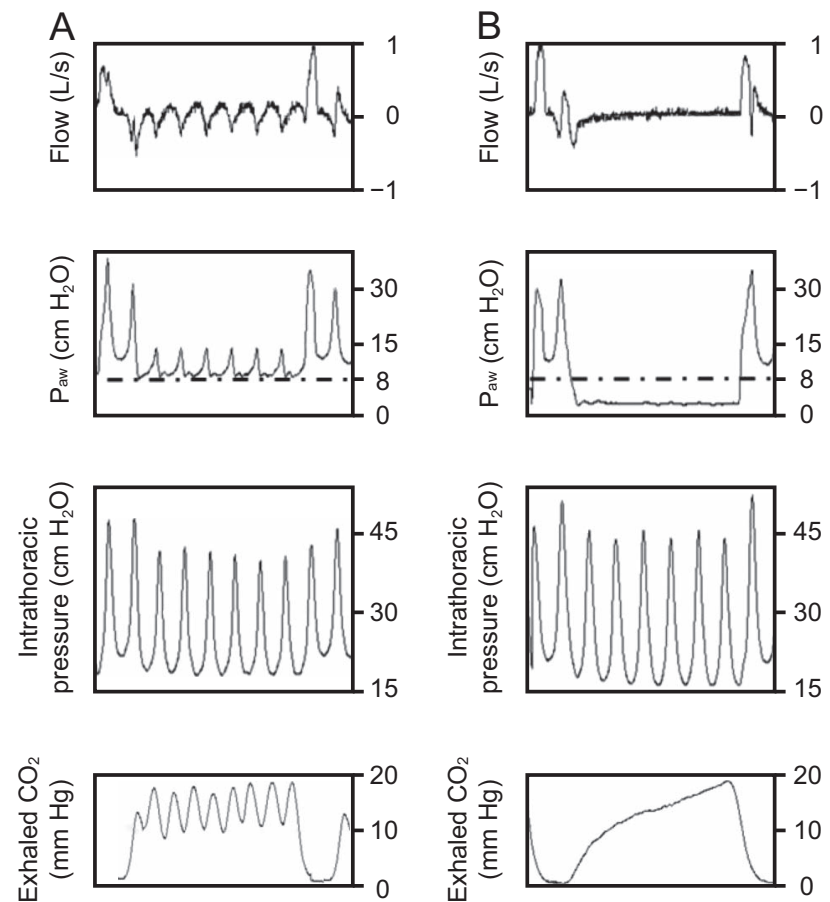

Fig. 3. Measures of airways occlusion in human cadaver. Typical patterns of pressure and flow transmission to airways by chest compression (measured with intrathoracic oscillations) at airways opening $(A)$ and disappearance of transmission when airways are closed (B). PEEP is applied above the airway closing (dotted line) pressure (A), then no PEEP is applied (B). The oscillation of $\mathrm{CO}_{2}$ induced by chest compression $(A)$ disappear when airways are closed (B). $\mathrm{P}_{\mathrm{aw}}=$ airway pressure.

\section{Perspectives}

CPR subverts the physiological rules regulating respiratory mechanics, which becomes complex to study and understand during chest compressions. The most relevant difference compared to the physiology of conventional ventilation is that, during $\mathrm{CPR}$, ventilation takes place below functional residual capacity, ${ }^{18}$ and promotes thoracic airway closure. ${ }^{36,38}$

Because this phenomenon can impair gas exchange and might impact outcome, ventilation strategies should counteract it. Because of its ability to prevent airway closure and ensure alveolar ventilation, the application of PEEP during CPR, using the $\mathrm{CO}_{2}$ signal to set it close to the airway closing pressure, could be a promising treatment method in humans. The possibility to compare strategies in an animal model and a representative human model (eg, Thiel cadavers) in parallel offers a unique opportunity to contribute new knowledge to the field.

\section{Summary}

Ventilation during CPR is still a broad field of research. Different models allow an increased understanding of the variety of physiological phenomena that occur during CPR. Recent physiological observations in this field challenge the current understanding of respiratory and circulatory interactions. The emerging concept of lung volume reduction and associated thoracic airway closure observed in clinical practice and reproduced in models may play a major role in the ventilation and gas exchange impairment observed during prolonged resuscitation. Hopefully, new discoveries will translate into clinical implementations of new ventilatory strategies, compatible with high-quality CPR (mainly continuous chest compressions) while improving lung protection and gas exchange.

\section{ACKNOWLEDGMENTS}

We are thankful for the support as well as the optimum research environment provided by Professor Gilles Bronchti and his team (Johanne Pellerin, Sophie Plante, Sonia Gauthier, and Marie-Eve Lemire) at the Laboratory of Anatomy of Université du Québec à Trois-Rivières. We are also grateful for the support provided by the Hospital of Annecy and Air Liquid in conducting this program of research. We also thank Thomas Piraino for his careful reading and appraisal of the manuscript.

\section{REFERENCES}

1. Zive DM, Schmicker R, Daya M, Kudenchuk P, Nichol G, Rittenberger JC, et al. Survival and variability over time from out of hospital cardiac arrest across large geographically diverse communities participating in the Resuscitation Outcomes Consortium. Resuscitation 2018;131:74-82.

2. Hawkes C, Booth S, Ji C, Brace-McDonnell SJ, Whittington A, Mapstone J, et al. Epidemiology and outcomes from out-of-hospital cardiac arrests in England. Resuscitation 2017;110:133-140.

3. Cordioli RL, Brochard L, Suppan L, Lyazidi A, Templier F, Khoury $\mathrm{A}$, et al. How ventilation is delivered during cardiopulmonary resuscitation: an international survey. Respir Care 2018;63(10):1293-1301.

4. Olasveengen TM, de Caen AR, Mancini ME, Maconochie IK, Aickin R, Atkins DL, et al. 2017 International Consensus on cardiopulmonary resuscitation and emergency cardiovascular care science with treatment recommendations summary. Circulation 2017;136(23): e424-e440.

5. Sall FS, De Luca A, Pazart L, Pugin A, Capellier G, Khoury A. To intubate or not: ventilation is the question. A manikin-based observational study. BMJ Open Respir Res 2018;5(1):e000261.

6. Cordioli RL, Grieco DL, Charbonney E, Richard J-C, Savary D. New physiological insights in ventilation during cardiopulmonary resuscitation. Curr Opin Crit Care 2019;25(1):37-44.

7. Henlin T, Michalek P, Tyll T, Hinds JD, Dobias M. Oxygenation, ventilation, and airway management in out-of-hospital cardiac arrest: a review. Biomed Res Int 2014;2014:376871.

8. Georgiou M, Papathanassoglou E, Xanthos T. Systematic review of the mechanisms driving effective blood flow during adult CPR. Resuscitation 2014;85(11):1586-1593.

9. Newell C, Grier S, Soar J. Airway and ventilation management during cardiopulmonary resuscitation and after successful resuscitation. Crit Care 2018;22(1): 190.

10. Safar P, Brown TC, Holtey WJ, Wilder RJ. Ventilation and circulation with closed-chest cardiac massage in man. JAMA 1961;176: 574-576.

11. Deakin CD, O’Neill JF, Tabor T. Does compression-only cardiopulmonary resuscitation generate adequate passive ventilation during cardiac arrest? Resuscitation 2007;75(1):53-59. 


\section{Ventilation DURING CPR}

12. McDannold R, Bobrow BJ, Chikani V, Silver A, Spaite DW, Vadeboncoeur T. Quantification of ventilation volumes produced by compressions during emergency department cardiopulmonary resuscitation. Am J Emerg Med 2018;36(9):1640-1644.

13. Dorph E, Wik L, Stromme TA, Eriksen M, Steen PA. Oxygen delivery and return of spontaneous circulation with ventilation:compression ratio 2:30 versus chest compressions only CPR in pigs. Resuscitation 2004;60(3):309-318.

14. Chandra NC, Gruben KG, Tsitlik JE, Brower R, Guerci AD, Halperin $\mathrm{HH}$, et al. Observations of ventilation during resuscitation in a canine model. Circulation 1994;90(6):3070-3075.

15. Idris AH, Banner MJ, Wenzel V, Fuerst RS, Becker LB, Melker RJ. Ventilation caused by external chest compression is unable to sustain effective gas exchange during CPR: a comparison with mechanical ventilation. Resuscitation 1994;28(2):143-150.

16. Saissy J-M, Boussignac G, Cheptel E, Rouvin B, Fontaine D, Bargues L, et al. Efficacy of continuous insufflation of oxygen combined with active cardiac compression-decompression during outof-hospital cardiorespiratory arrest. Anesthesiology 2000;92(6):15231530.

17. Brochard L, Boussignac G, Adnot S, Bertrand C, Isabey D, Harf A. Efficacy of cardiopulmonary resuscitation using intratracheal insufflation. Am J Respir Crit Care Med 1996;154(5):1323-1329.

18. Cordioli RL, Lyazidi A, Rey N, Granier J-M, Savary D, Brochard L, et al. Impact of ventilation strategies during chest compression. An experimental study with clinical observations. J Appl Physiol 2016; 120(2):196-203.

19. Duchatelet C, Kalmar AF, Monsieurs KG, Hachimi-Idrissi S. Chest compressions during ventilation in out-of-hospital cardiac arrest cause reversed airflow. Resuscitation 2018;129:97-102.

20. Rodarte JR, Hyatt RE, Cortese DA. Influence of expiratory flow on closing capacity at low expiratory flow rates. J Appl Physiol 1975; 39(1):60-65.

21. Coudroy R, Lu C, Chen L, Demoule A, Brochard L. Mechanism of airway closure in acute respiratory distress syndrome: a possible role of surfactant depletion. Intensive Care Med 2019;45(2):290-291.

22. Chen L, Del Sorbo L, Grieco DL, Shklar O, Junhasavasdikul D, Telias I, et al. Airway closure in acute respiratory distress syndrome: an underestimated and misinterpreted phenomenon. Am J Respir Crit Care Med 2018;197(1):132-136.

23. Moore JC, Lamhaut L, Hutin A, Dodd KW, Robinson AE, Lick MC, et al. Evaluation of the Boussignac cardiac arrest device (B-card) during cardiopulmonary resuscitation in an animal model. Resuscitation 2017;119:81-88.

24. Markstaller K, Rudolph A, Karmrodt J, Gervais HW, Goetz R, Becher $\mathrm{A}$, et al. Effect of chest compressions only during experimental basic life support on alveolar collapse and recruitment. Resuscitation 2008 Oct; 79(1):125-132.

25. Hodgkin BC, Lambrew CT, Lawrence FH3, Angelakos ET. Effects of PEEP and of increased frequency of ventilation during CPR. Crit Care Med 1980;8(3):123-126.

26. McCaul C, Kornecki A, Engelberts D, McNamara P, Kavanagh BP. Positive end-expiratory pressure improves survival in a rodent model of cardiopulmonary resuscitation using high-dose epinephrine. Anesth Analg 2009;109(4):1202-1208.

27. Berg RA, Hilwig RW, Kern KB, Ewy GA. "Bystander" chest compressions and assisted ventilation independently improve outcome from piglet asphyxial pulseless "cardiac arrest". Circulation 2000; 101(14):1743-1748.

28. Vognsen M, Fabian-Jessing BK, Secher N, Lofgren B, Dezfulian C, Andersen LW, et al. Contemporary animal models of cardiac arrest: a systematic review. Resuscitation 2017;113:115-123.

29. Halperin HR, Brower R, Weisfeldt ML, Tsitlik JE, Chandra N, Cristiano LM, et al. Air trapping in the lungs during cardiopulmonary resuscitation in dogs: a mechanism for generating changes in intrathoracic pressure. Circ Res 1989;65(4):946-954.

30. Rudikoff MT, Maughan WL, Effron M, Freund P, Weisfeldt ML. Mechanisms of blood flow during cardiopulmonary resuscitation. Circulation 1980;61(2):345-352.

31. Yannopoulos D, McKnite S, Aufderheide TP, Sigurdsson G, Pirrallo RG, Benditt D, et al. Effects of incomplete chest wall decompression during cardiopulmonary resuscitation on coronary and cerebral perfusion pressures in a porcine model of cardiac arrest. Resuscitation 2005;64(3):363-372.

32. Chang MW, Coffeen P, Lurie KG, Shultz J, Bache RJ, White CW. Active compression-decompression CPR improves vital organ perfusion in a dog model of ventricular fibrillation. Chest 1994;106(4): 1250-1259.

33. Lurie KG, Coffeen P, Shultz J, McKnite S, Detloff B, Mulligan K. Improving active compression-decompression cardiopulmonary resuscitation with an inspiratory impedance valve. Circulation 1995; 91(6):1629-1632.

34. Voelckel WG, Lurie KG, Zielinski T, McKnite S, Plaisance P, Wenzel V, et al. The effects of positive end-expiratory pressure during active compression decompression cardiopulmonary resuscitation with the inspiratory threshold valve. Anesth Analg 2001;92(4):967974.

35. Segal N, Voiglio EJ, Rerbal D, Jost D, Dubien P-Y, Lanoe V, et al. Effect of continuous oxygen insufflation on induced-gastric air volume during cardiopulmonary resuscitation in a cadaveric model. Resuscitation 2015;86:62-66.

36. Charbonney E, Delisle S, Savary D, Bronchti G, Rigollot M, Drouet A, et al. A new physiological model for studying the effect of chest compression and ventilation during cardiopulmonary resuscitation: the Thiel cadaver. Resuscitation 2018;125:135-142.

37. Savary D, Charbonney E, Delisle S, Marceau R, Paul O, Gilles B, et al. Capnographic waveforms obtained in experimental Thiel cadaver model after intubation. Resuscitation 2017;116:e1-e2.

38. Grieco DL, Brochard L, Drouet A, Telias I, Delisle S, Bronchti G, et al. Intrathoracic airway closure impacts $\mathrm{CO} 2$ signal and delivered ventilation during cardiopulmonary resuscitation. Am J Respir Crit Care Med 2019;199(6):728-737.

39. Ornato JP, Bryson BL, Donovan PJ, Farquharson RR, Jaeger C. Measurement of ventilation during cardiopulmonary resuscitation. Crit Care Med 1983;11(2):79-82.

40. Jellinek H, Krenn H, Oczenski W, Veit F, Schwarz S, Fitzgerald RD. Influence of positive airway pressure on the pressure gradient for venous return in humans. J Appl Physiol 2000;88(3):926-932.

41. Gutierrez JJ, Leturiondo M, Ruiz de Gauna S, Ruiz JM, Leturiondo LA, Gonzalez-Otero DM, et al. Enhancing ventilation detection during cardiopulmonary resuscitation by filtering chest compression artifact from the capnography waveform. PLoS ONE 2018;13(8): $\mathrm{e} 0201565$. 